(C) 1981. The Genetical Society of Great Britain

\title{
BIRTH CONTROL-SEX PREFERENCE AND SEX RATIO
}

\author{
MIGUEL A. TORO* \\ School of Biological Sciences, University of Sussex, Brighton, BN1 9QG, U.K.
}

Received 7.v.81

\section{INTRODUCTION}

Population size is a function of birth rate, which is lower in economically developed countries, apparently due to family planning. In the last few years, there have been a considerable number of studies of the factors determining the number of children per family. In some populations it has been found that combinations of sexes of children influence the family size. It is generally assumed that many parents may want their families to include at least one boy (type I) or at least one boy and one girl (type II) (see Goodman, 1961). In the second case, if the first two children are of the same sex these parents might feel more inclined to increase their families beyond two children than if the first two children were a boy and a girl.

This preference for a child of each sex apparently exists in British (Thomas, 1951), French (Calot and Henry, 1972), American (Freedman et al., 1960), Brazilian (Lloyd and Gray, 1969) and Spanish (Medina, 1977) families, but Ayala and Falk (1971) did not find this preference in a study of families of college students in New England.

Nevertheless, the relationship between this preference and the sex ratio is not clear in most studies despite the clarifying article of Goodman (1961), who studied the statistical aspects of the question. He concluded that the overall effect of birth control on the sex ratio will depend upon the particular kinds of preferences for male or female offspring, the ways in which these preferences affect the parents' decision to have another child, the distribution of the probability of bearing a boy and the relation between family size and this probability.

In this note, I generalise the results of Goodman (1961), and ask the following additional question: if we assume that the sex ratio is under genetic control (see Edwards, 1970; Teitelbaum, 1972), in which direction can we expect it to evolve in response to the pattern of birth control? We can answer this question by means of the evolutionarily stable strategy (ESS) concept (Maynard Smith, 1978, p. 147). We look for a sex ratio $r$ (defined as the frequency of male zygotes), such that if the population sex ratio is in fact $r$, then no mutant allele which produces a sex ratio $r^{\prime}$ different from $r$ is as successful as the typical allele which produces the sex ratio $r$.

\section{Situation A: MALE PREFerenCE}

This situation corresponds to family type I in Goodman's notation. The preference for male offspring might lead to the decision of a married couple to continue to bear children until a boy is born, and then use birth control

\footnotetext{
* Present address: Departamento de Genética Cuantitativa, Instituto Nacional de Investigaciones Agrarias, Madrid, Spain.
} 
so as to bear no further children. I assume also that the maximum number of children that it is possible to bear is $n$ and that the preferences themselves are fixed and not subject to selection.

In this case it can easily be shown that if a family has an expected sex ratio of $r$, and we assume perfect birth control, the expected size of this family will be

$$
\begin{aligned}
& r+r(1-r) 2+r(1-r)^{2} 3+\cdots+r(1-r)^{n-1} n+(1-r)^{n} n \\
& \quad=1+(1-r)+(1-r)^{2}+\cdots+(1-r)^{n-1}=\frac{1-(1-r)^{n}}{r} .
\end{aligned}
$$

Let us consider a genetically homogeneous random mating population of genotype $a a$ with a sex ratio of $r$. A rare dominant gene $A$ arises by mutation that causes $A a$ females to produce a sex ratio of $r^{\prime}$ (similar conclusions follow for a gene expressed only in males). The frequency of $A a$ is $P$ among females and $p$ among males. We can ignore $A A$ individuals since $P$ and $p$ are small.

Table 1 shows the expected number of offspring corresponding to each type of mating, taking into account the expected sex ratio as determined by maternal genotype.

If the frequencies in the next generation are $P^{\prime}, p^{\prime}$, then

$$
\begin{aligned}
P^{\prime} & \approx \frac{1}{2} \frac{r\left(1-r^{\prime}\right)\left[1-\left(1-r^{\prime}\right)^{n}\right]}{r^{\prime}(1-r)\left[1-(1-r)^{n}\right]} P+\frac{1}{2} p \\
p^{\prime} & \approx \frac{1}{2} \frac{1-\left(1-r^{\prime}\right)^{n}}{1-(1-r)^{n}} P+\frac{1}{2} p .
\end{aligned}
$$

Adding the two equations we obtain

$$
P^{\prime}+p^{\prime} \approx P+p+Z P
$$

where

$$
Z=\frac{1}{2} \frac{r\left(1-r^{\prime}\right)\left[1-\left(1-r^{\prime}\right)^{n}\right]}{r^{\prime}(1-r)\left[1-(1-r)^{n}\right]}+\frac{1}{2} \frac{\left[1-\left(1-r^{\prime}\right)^{n}\right]}{\left[1-(1-r)^{n}\right]}-1
$$

The sex ratio is an ESS only if $\left(\partial Z / \partial r^{\prime}\right)_{r^{\prime}=r}=0$ (Maynard Smith, 1978, p. 161). This requires $r$ to satisfy the following equation

$$
\frac{(1-r)^{n}(2 n r+1)-1}{2 r(1-r)\left[1-(1-r)^{n}\right]}=0 .
$$

Table 2 shows some numerical solutions of this equation. In the Appendix, I give a more detailed account of the ESS approach and I also prove that for each $n$ there is only one relevant solution of equation (4).

These results show that alleles reducing the sex ratio from $1: 1$ will always increase in frequency due to selection for large family size. This implies that male preference increases the number of females if we assume that the sex ratio is genetically controlled. It is obvious that the opposite must be true if there is female preference; the parents decide that if their first child is a boy, they will continue to bear children, and if their first child is a girl, they will bear no further children. 


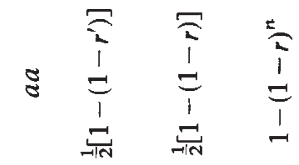

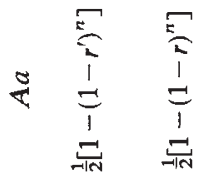
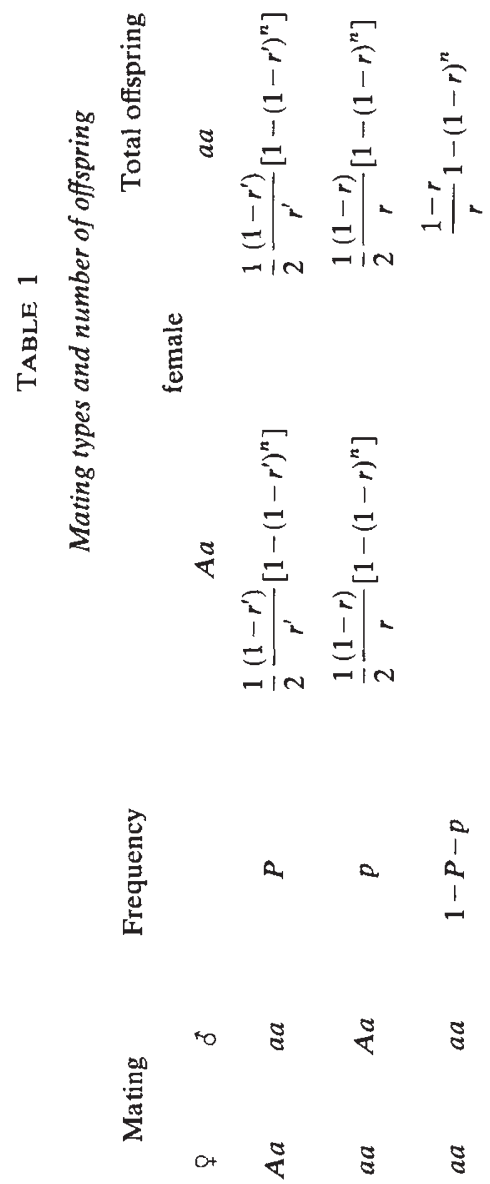
TABLE 2

Dependence of $\mathrm{r}$ on $\mathrm{n}$

$\begin{array}{rc}n & r \\ 2 & 0 \cdot 3596 \\ 3 & 0 \cdot 2802 \\ 4 & 0 \cdot 2293 \\ 5 & 0 \cdot 1940 \\ 6 & 0 \cdot 1680 \\ 7 & 0 \cdot 1483 \\ 8 & 0 \cdot 1327 \\ 9 & 0 \cdot 1200 \\ 10 & 0 \cdot 1096 \\ 15 & 0 \cdot 0763 \\ 20 & 0 \cdot 0585\end{array}$

\section{SituATION B: PREFERENCE FOR AT LEAST ONE BOY AND ONE GIRL}

This model corresponds with couples of type II in Goodman's notation. In this situation, if the first child is a girl, children will continue to be born until a boy is born and if the first child is a boy, the parents will continue to bear children until a girl is born.

If we assume perfect birth control and a maximum family size of $n$, the expected family size of a family with a sex ratio of $r$ will be

$$
\begin{aligned}
r(1-r) & +(1-r) r 2+r^{2}(1-r)+(1-r)^{2} r 3+\cdots+r^{n-1}+(1-r)^{n-1} n \\
= & r^{n-1}+r^{n-2}+\cdots+r^{2}+r+r+(1-r)^{n-1}+(1-r)^{n-2} \\
& +\cdots+(1-r)^{2}+(1-r)+(1-r) \\
= & 1+r\left[\frac{1-r^{n-2}}{1-r}\right]+(1-r)\left[\frac{1-(1-r)^{n-2}}{r}\right] .
\end{aligned}
$$

In this model, after some tedious calculation the ESS strategy can be shown to satisfy the following equation

$$
\begin{aligned}
& \left(\frac{\partial Z}{\partial r^{\prime}}\right)_{r^{\prime}=r}= \\
& \quad \frac{(1-r)^{n}(0 \cdot 50+r n-r)+r^{n}(0 \cdot 50-n+r n-r)+(r-0 \cdot 50)\left(1+r-r^{2}\right)}{r(1-r)\left[1-r+r^{2}-r^{n}-(1-r)^{n}\right]} .
\end{aligned}
$$

Table 3 shows some numerical solutions of this equation.

If we carry out an analysis similar to that performed for situation $\mathrm{A}$, it is possible to show that the solution $r=0.50$ is always unstable and the others are only locally stable. It is clear then, that no sex ratio could be globally stable in this system.

This situation seems very odd but we can see an intuitive reason that justifies this result. Selection for sex ratio under these circumstances has two components: (a) The family size, maximum for $r=0$ or 1 and minimum for $r=0 \cdot 5$. (b) The Fisherian component (Fisher, 1958): In a population with an excess of males, a genotype producing an excess of females will be selected for. In situation $B$, it is not possible to optimize the two components simultaneously. For example, a sex ratio of $r$ always will be 
TABLE 3

Dependence of $\mathrm{r}$ on $\mathrm{n}$

$\begin{array}{rccc}n & & r & \\ 5 & - & 0.5 & - \\ 6 & 0.2764 & 0.5 & 0.7236 \\ 7 & 0.2097 & 0.5 & 0.7902 \\ 8 & 0.1735 & 0.5 & 0.8265 \\ 9 & 0.1494 & 0.5 & 0.8506 \\ 10 & 0.1318 & 0.5 & 0.8682 \\ 15 & 0.0845 & 0.5 & 0.9155 \\ 20 & 0.0628 & 0.5 & 0.9372\end{array}$

invadable by a sex ratio of $1-r$, because if we replace $r^{\prime}$ by $1-r$ in equation (1) of the Appendix we have

$$
Z=\frac{1}{2} \frac{r f(1-r)}{(1-r) f(r)}+\frac{1}{2} \frac{(1-r) f(1-r)}{r f(r)}-1
$$

but $f(1-r)=f(r)$ and so

$$
Z=\frac{1-4 r(1-r)}{2 r(1-r)},
$$

which is always positive for $r \neq 0.50$.

Nevertheless, from the behaviour of equation (1) of the Appendix it is easy to show that a mixed strategy is evolutionarily stable: half of the mothers producing only males $(r=1)$ and the other half producing only females $(r=0)$. In such a population other alleles confering any other sex ratio on their bearers will be less fit. In the absence of any genetic constraint the population sex ratio will remain 0.5 but the variance of the sex ratio between families will increase and finally there will be an equal proportion of families with only males and only females.

The situations presented above are similar to those of reproductive compensation or social selection. It has been observed that illness or death of a child due to a genetic disease can induce the parents to compensate for this child by having more children (reproductive compensation, Fisher, 1958; Charlesworth, 1977), or may cause genetically normal individuals, such as other sibs in an affected family to have lower fertility (social selection, Yokoyama, 1980). In our case it is the desire of having a boy or at least one boy and one girl that increases the family size.

In recent years there has been an increasing interest in situations in which a sex ratio different from $1: 1$ could be evolutionarily stable. Predictions of other sex ratios have been made for local mate competition (Hamilton, 1967; Bulmer and Taylor, 1980) and variation in offspring quality as a result of the mother's reproductive condition (Charnov et al., 1981). We have shown here that, under birth control and sex preference, either a distorted sex ratio can be an ESS, or that no sex ratio can become fixed in the population.

Unfortunately, without details of the magnitude of the genetic variance in sex ratio and the ways in which the preferences for male or female offspring affect the decision as to whether or not to have another child it 
is not possible to make even an approximation of the expected historical change in the sex ratio by these mechanisms.

Acknowledgements.-I am greatly indebted to Brian Charlesworth for showing me how to tackle sex ratio problems and for his continuous assistance. I would also like to thank $J$. Maynard Smith for his comments.

\section{REFERENCES}

AyAlA, F. J., AND FAlK, C. T. 1971. Sex of children and family size. J. Hered., 62, 57-59. BULMER, M. G., AND TA YLOR, P. D. 1980. Dispersal and the sex ratio. Nature, 284, 448-449. CALOT, G., AND HENRY, L. 1972. Nuptialité et fecondité des mariages en France d'après l'enquête de 1962. Population, 27, 191-208.

CHARLESWORTH, B. 1977. Population genetics, demography and the sex ratio. In Measuring Selection in Natural Populations, eds. F. B. Christiansen and T. M. Fenchel. SpringerVerlag, Berlin.

CHARNOV, E. L., LOS-DENHARTOGH, R. L., JONES, W. T., AND VAN DEN ASSEM, J. 1981. Sex ratio evolution in a variable environment. Nature, 289, 27-33.

EDWARDS, A. W. F. 1970 . The search for genetic variability of the sex ratio. $J$, biosoc. Sci. Suppl., 2, 55-60.

FISHER, R. A. 1958. The genetical theory of natural selection, 2nd ed. Dover, New York.

FREEDMAN, D. S., FREEDMAN, R., AND WHELPTON, P. K. 1960. Size of family and preference for children of each sex. Amer. J. Sociol., 66, 141-146.

GOODMAN, L. A. 1961. Some possible effects of birth control on the human sex ratio. Ann. Human Genet., 25, 75-81.

HAMILTON, W. D. 1967. Extraordinary sex ratios. Science, 156, 477-488.

LLOYD, R. C., AND GRAY, E. 1969. A statistical study of the human sex ratio. J. Hered., $60,329-331$.

MAYNARD SMITH, J. 1978. The Evolution of Sex. Cambridge University Press, Cambridge. MEDINA, J. R. 1977. Male preference and family size. J. Hered., 68, 260-261.

TEITELBAUM, M. S. 1972. Factors associated with the sex ratio in human populations. In The Structure of Human Populations, eds. G. A. Harrison and A. J. Boyce. Oxford University Press, Oxford.

THOMAS, M. H. 1951. Sex pattern and size of family. Br. Med. J., 1, 733-734.

YOKOYAMA, S. 1980. The effect of social selection on population dynamics of rare deleterious genes. Heredity, 45, 271-280.

\section{APPENDIX}

Mathematically, the method for finding the ESS is the following. Let $f(r)$ and $f\left(r^{\prime}\right)$ be the family sizes corresponding to the expected sex ratios of $r$ and $r^{\prime}$. Then

$$
Z=\frac{1}{2} \frac{\left(1-r^{\prime}\right) f\left(r^{\prime}\right)}{(1-r) f(r)}+\frac{1}{2} \frac{r^{\prime} f\left(r^{\prime}\right)}{r f(r)}-1
$$

We want to find $r$, such that $Z$ is a maximum and equal to 0 when $r^{\prime}=r$. This means that the sex ratio $r$ is an ESS if and only if

$$
\left(\frac{\partial Z}{\partial r^{\prime}}\right)_{r^{\prime}=r}=0 \text { and }\left(\frac{\partial^{2} Z}{\partial r^{\prime 2}}\right)_{r^{\prime}=r}<0 .
$$

After some algebraic manipulation we have

$$
\begin{aligned}
& \left(\frac{\partial Z}{\partial r^{\prime}}\right)_{r^{\prime}=r}=\frac{2 r(1-r)\left(\partial f\left(r^{\prime}\right) / \partial r^{\prime}\right)_{r^{\prime}=r}+(1-2 r) f\left(r^{\prime}\right)}{2 r(1-r) f(r)}=0 \\
& \left(\frac{\partial^{2} Z}{\partial r^{\prime 2}}\right)_{r^{\prime}=r}=\frac{1}{f(r)}\left(\frac{\partial^{2} f\left(r^{\prime}\right)}{\partial r^{\prime 2}}\right)_{r^{\prime}=r}+\frac{(1-2 r)}{r(1-r) f(r)}\left(\frac{\partial f^{\prime}(r)}{\partial r^{\prime}}\right)_{r^{\prime}=r}
\end{aligned}
$$


In situation $\mathrm{A}$, the relationship between family size and sex ratio is

$$
f(r)=\frac{1-(1-r)^{n}}{1-r}
$$

This yields the conditions for $r$ to be an ESS

$$
\frac{(1-r)^{n}(2 n r+1)-1}{2 r(1-r)\left[1-(1-r)^{n}\right]}=0
$$

and

$$
\frac{n r(1-r)^{n-1} r(1-n)+(1-2 r)(3-2 r)+(1-2 r)(1-r)^{n}-1}{r^{2}(1-r)\left[1-(1-r)^{n}\right]}<0 .
$$

Condition (4b) can be simplified using (4a) and gives

$$
\frac{n r(1-r)^{n-1}[1-r(n-1)]}{r^{2}(1-r)\left[1-(1-r)^{n}\right]}<0
$$

or

$$
r>\frac{1}{n+1}
$$

It is easy to check that the numerical values of table 2 satisfy the two conditions.

The uniqueness of the solution of equation (4a) is also very easy to prove. Since neither 0 nor 1 are roots of the equation, and the denominator is always positive between $0<r<1$, we only need to consider the function

$$
\varphi(r)=(1-r)^{n}(2 n r+1)-1 \text {. }
$$

Looking at the first derivative of $\varphi(r)$ we can sketch the behaviour of $\varphi(r)$ in the interval $0<r<1$ and see that it crosses the real axis only once. 